\title{
FAKTOR - FAKTOR YANG BERHUBUNGAN DENGAN MUTU PELAYANAN KESEHATAN DI RUMAH SAKIT STELLA MARIS BINTANG LAUT KECAMATAN TELUK DALAM KABUPATEN NIAS SELATAN
}

\author{
Tiwanto Dakhi' ${ }^{1}$, Mappeaty Nyorong ${ }^{2}$, Juliandi Harahap ${ }^{3}$ \\ 1,2,3 Institut Kesehatan Helvetia, Medan \\ Email : tiwantodakhi@gmail.com
}

\begin{abstract}
Abstrak
Rumah sakit memiliki peran yang sangat strategis dalam upaya mempercepat peningkatan derajat kesehatan masyarakat. Paradigma baru pelayanan kesehatan mensyaratkan rumah sakit memberikan pelayanan berkualitas sesuai kebutuhan dan keinginan pasien dengan tetap mengacu pada kode etik profesi dan medis. Tujuan penelitian untuk mengetahui hubungan reliability, assurance, tangibles, emphaty, responsiveness dengan mutu pelayanan kesehatan di Rumah Sakit Stella Maris Bintang Laut Kecamatan Teluk Dalam Kabupaten Nias Selatan. Desain penelitian menggunakan metode kuantitatif yang dilakukan survei analitik dengan pendekatan cross sectional study. Populasi dalam penelitian ini adalah pasien yang datang berobat yaitu 512 responden. Sampel menggunakan sistem accidental sampling sebanyak 83 pasien. Analisis data menggunakan analisis univariat, bivariat dan multivariat. Hasil penelitian menunjukkan variabel reliability $p=0,010$, assurance $p=0,027$, tangibles $p=0,000$, empathy $p=0,027$, responsiveness $p=0,000$. Sedangkan faktor yang dominan yang berhubungan dengan mutu pelayanan adalah responsiveness $p=0,000,95 \% \mathrm{CI}=6,092$ 154,611 dengan OR 30,691. Kesimpulan dari penelitian ini adalah ada hubungan reliability, assurance, tangible, emphaty, responsiveness dengan pelayanan di Rumah Sakit Stella Maris Bintang Laut Kecamatan Teluk Dalam Kabupaten Nias Selatan. Disarankan kepada Rumah Sakit Stella Maris Bintang Laut Kecamatan Teluk Dalam Kabupaten Nias Selatan agar meningkatakan mutu pelayanan pada dimensi responsiveness, yang dirasa kurang baik dari pemberi pelayanan (petugas kesehatan) kepada pasien rawat jalan dalam hal ini dapat memberikan pelatihan kepada petugas kesehatan agar lebih memaksimalkan dan mempertahankan kualitas yang sudah baik agar kepuasan pelayanan kesehatan pasien dapat tercapai secara maksimal.
\end{abstract}

Kata Kunci: Reliability, Assurance, Tangibles, empathy, Responsiveness, Mutu Pelayanan Kesehatan

\begin{abstract}
Hospitals have a very strategic role in the effort to accelerate the improvement of public health status. The new paradigm of health care requires hospitals to provide quality services according to the needs and desires of patients while still referring to the professional and medical code of ethics. The purpose of the study was to determine the relationship between reliability, assurance, tangibles, empathy, responsiveness with the quality of health services at the Stella Maris Bintang Laut Hospital, Teluk Dalam District, South Nias Regency. The research design used a quantitative method which was carried out by an analytical survey with a cross sectional study approach. The population in this study were patients who came for treatments 512 respondents. The sample used accidental sampling system as many as 83 patients. Data analysis used univariate, bivariate and multivariate analysis. The results showed that reliability $p=0.010$, assurance $p=0.027$, tangibles $p=0.000$, empathy $p=0.027$, responsiveness $p=0.000$. While the dominant factor related to service quality is responsiveness $p=0.000,95 \%$ CI $=6.092-154.611$ with OR 30.691. The conclusion of this study is that there is a relationship of reliability, assurance, tangible, empathy, responsiveness with services at the Stella Maris Bintang Laut Hospital, Teluk Dalam District, South Nias Regency. It is recommended to the Stella Maris Bintang Laut Hospital, Teluk Dalam District, South Nias Regency to improve the quality of service on the responsiveness dimension, which is considered less good
\end{abstract}


from service providers (health workers) to outpatients in this case can provide training to health workers to maximize and maintain good quality so that patient health service satisfaction can be achieved maximally.

Keywords: Reliability, Assurance, Tangibles, empathy, Responsiveness, Quality of Health Services

\section{Pendahuluan}

Rumah sakit memiliki peran yang sangat strategis dalam upaya mempercepat peningkatan derajat kesehatan masyarakat. Paradigma baru pelayanan kesehatan mensyaratkan rumah sakit memberikan pelayanan berkualitas sesuai kebutuhan dan keinginan pasien dengan tetap mengacu pada kode etik profesi dan medis. Dalam perkembangan teknologi yang pesat dan persaingan yang semakin ketat, maka rumah sakit dituntut untuk melakukan peningkatan kualitas pelayanannya (1).

Definisi sehat menurut World Health Organization (WHO) adalah keadaan sejahtera, sempurna dari fisik, mental, dan sosial yang tidak terbatas hanya pada bebas dari penyakit dan kelemahan saja. Kesehatan merupakan hak asasi manusia dan salah satu unsur untuk mencapai kesejahteraan yang sesuai dengan salah satu cita-cita bangsa Indonesia dan untuk menunjang kesehatan masyarakat dengan derajat kesehatan yang setinggi-tingginya. Upaya tersebut hendaknya dilakukan dengan prinsip non diskriminatif, partisipastif, perlindungan dan berkelanjutan yang bertujuan untuk membentuk sumber daya manusia Indonesia, peningkatan ketahanan dan daya saing bangsa dan pembangunan nasional. Masyarakat saat ini telah banyak menginginkan mendapatkan pelayanan dan informasi tentang kesehatan yang baik, lengkap, mudah dan terjangkau (2).

Berdasarkan Keputusan Menteri Kesehatan Republik Indonesia Nomor : 129/MENKES/SK/II/2018 tentang Standar Pelayanan Minimal Rumah Sakit. Rumah sakit sebagai salah satu fasilitas pelayanan kesehatan perorangan merupakan bagian dari daya kesehatan yang sangat di perlukan dalam mendukung. Dengan kebijakan ini bidang Kesehatan mengalami perubahan yang cukup mendasar dari sebelumnya sebagaimana ditetapkan dengan Permenkes Nomor 43 Tahun 2016 tentang Standar Pelayanan Minimal.

Pengukuran indikator pelayanan rumah sakit disebutkan dalam Permenkes Nomor 1171/Menkes/PER/VI/2011 tentang Sistem Informasi Rumah Sakit menyebutkan indikator pelayanan Rumah Sakit dinyatakan dengan Angka Penggunaan Tempat Tidur (Bed Occupancy Rate), rata rata lamanya pasien dirawat (Average Length Of Stay), Angka Perputaran Tempat Tidur (Bed Turn Over), Tenggang Perputaran (Turn Over Interval), Angka Kematian 48 jam setelah dirawat (Net Death Rate) dan Gross DR (4).

Menurut Nursalam, indikasi kualitas pelayanan kesehatan di rumah sakit dapat tercermin dari kepuasan pasien atas pelayanan kesehatan yang telah diterimanya. Kepuasan pasien pada kualitas pelayanan merupakan penilaian menyeluruh atas keunggulan suatu jasa atau pelayanan. Kepuasan adalah perasaan senang seseorang yang berasal dari perbandingan antara kesenangan terhadap aktivitas dan suatu layanan yang diterima dengan harapannya yang muncul setelah membandingkan antara persepsi atau kesannya terhadap kinerja atau hasil suatu produk dan harapan-harapannya, demikian juga halnya dalam kualitas pelayanan administrasi (5).

Salah satu rumah sakit yang memberikan pelayanan kesehatan di Sumatera Utara yang berlokasi di Kota Teluk Dalam Nias Selatan adalah Rumah Sakit Stella Maris Bintang Laut. Rumah Sakit ini sebagai rumah sakit milik Yayasan, yang berklasifikasi Rumah Sakit Type $\mathrm{C}$ yang menyelenggarakan pelayanan spesialistik dan subspesialistik. 
Berdasarkan data pasien di Rumah Sakit Stella Maris Bintang Laut Periode Tahun 2019 - 2020, diketahui jumlah pasien yang berkunjunga ke Rumah Sakit Stella Maris Bintang Laut mengalami penurunan yang signifikan pada tahun 2020 yaitu sebanyak 1519 pasien rawat jalan dibandingkan kunjungan pada tahun 2019 yaitu sebanyak 2550 pasien rawat jalan. Hal ini menunjukan bahwa dari tahun 2020 hingga tahun 2021 mengalami penurunan kunjungan pasien yang di indikasikan bahwa mutu pelayanan yang belum maksimal dan perlu di tingkatkan lagi. Hal ini dapat di sebabkan oleh faktor eksternal dan faktor internal. Faktor eksternal yaitu dimana jumlah pasien yang sakit berkurang atau faktor internal yakni pelayanan BPJS dihentikan, pelayanan yang di berikan kepada pasien belum maksimal sehingga pasien merasa kurang puas mutu pelayanan dan untuk enggan berobat.

Dari hasil survei awal yang dilakukan oleh peneliti pada data pelayanan mutu kesehatan di Rumah Sakit Stella Maris Bintang Laut Kecamatan Teluk Dalam Kabupaten Nias Selatan tercatat masih banyak keluhan pasien terkait pelayanan mutu kesehatan salah satu dalam pendaftaran, pelayanan rawat jalan, instalasi farmasi, pelayanan penunjang dalam hal respon time dokter dan perawat lambat, kurang kejelasan dan keterbukaan informasi, keramahan petugas kurang, dan ruang tunggu kurang nyaman.

Berdasarkan urain di atas, maka peneliti tertarik untuk melakukan penelitian yang berjudul "Faktor- Faktor yang Berhubungan dengan Mutu Pelayanan Kesehatan di Rumah Sakit Stella Maris Bintang Laut Kecamatan Teluk Dalam Kabupaten Nias Selatan"

\section{Metode Penelitian}

Desain penelitian menggunakan metode kuantitatif yang dilakukan survei analitik dengan pendekatan cross sectional study, yang merupakan rancangan penelitian dimana variabel bebas dan variabel terikat diukur dan dikumpulkan dalam waktu yang bersamaan bertujuan untuk mengetahui faktor yang berhubungan dengan mutu pelayanan Kesehatan Rumah Sakit Stella Maris Bintang Laut Kecamatan Teluk Dalam Kabupaten Nias Selatan. Populasi dalam penelitian ini adalah seluruh pasien yang datang berobat ke Instalasi Rawat Jalan Rumah Sakit Stella Maris Bintang Laut Kecamatan Teluk Dalam Kabupaten Nias Selatan berjumlah rata-rata 512 orang perbulan dari total kunjungan pasien rawat jalan sebesar 512 pasien pada tahun 2021. Teknik pengambilan sampel menggunakan sistem accidental sampling diperoleh jumlah sampel sebanyak 83 responden pasien rawat jalan

\section{Hasil Penelitian}

\section{Analisis Univariat}

\section{Karakteristik Responden}

Responden dalam penelitian ini adalah seluruh pasien yang datang berobat ke Instalasi Rawat Jalan Rumah Sakit Stella Maris Bintang Laut Kecamatan Teluk Dalam Kabupaten Nias Selatan sebanyakk 83 orang.

Tabel 1. Distribusi Karakteristik pasien di Instalasi Rawat Jalan Rumah Sakit Stella Maris Bintang Laut Kecamatan Teluk Dalam Kabupaten Nias Selatan

\begin{tabular}{lcc}
\hline Karakteristik & Frekuensi (f) & Persentase (\%) \\
\hline Umur & 33 & \\
27-31 Tahun & 16 & 39,8 \\
32-36 Tahun & 20 & 19,3 \\
37-41 Tahun & 7 & 42,1 \\
42-46 Tahun & 7 & 8,4 \\
> 46 Tahun & & 8,4 \\
Jenis Kelamin & &
\end{tabular}




\begin{tabular}{lcc} 
Laki-laki & 47 & 56,6 \\
Perempuan & 36 & 43,4 \\
Pendidikan & & \\
SMA & 17 & 20,5 \\
S1 & 33 & 39,8 \\
S2 & 28 & 33,7 \\
S3 & 5 & 6,0 \\
Pekerjaan & & \\
Pegawai Negeri (PNS) & 10 & 12,0 \\
Pegawai Swasta & 7 & 8,4 \\
Ibu Rumah Tangga (IRT) & 15 & 18,1 \\
Wiraswasta & 29 & 34,9 \\
Lainnya & 22 & 26.5 \\
\hline Total & $\mathbf{8 3}$ & $\mathbf{1 0 0 , 0}$ \\
\hline
\end{tabular}

\section{Analisis Bivariat}

Analisis bivariat dalam penelitian ini untuk mengetahui hubungan variabel independen (Reliability, assurance, tangibles, empathy dan responsiveness) dengan mutu pelayanan di Instalasi Rawat Jalan Rumah Sakit Stella Maris Bintang Laut Kecamatan Teluk Dalam Kabupaten Nias Selatan disajikan sebagai berikut :

Tabel 2. Hubungan Reliability dengan Mutu Pelayanan di Instalasi Rawat Jalan Rumah Sakit Stella Maris Bintang Laut Kecamatan Teluk Dalam Kabupaten Nias Selatan

\begin{tabular}{ccccccccc}
\hline \multirow{2}{*}{ Reliability } & \multicolumn{4}{c}{ Mutu Pelayanan } & \multicolumn{2}{c}{ Total } & \multirow{2}{*}{$\boldsymbol{p}$ value } \\
\cline { 2 - 6 } & \multicolumn{2}{c}{ Kurang } & \multicolumn{2}{c}{ Baik } & & \\
\cline { 2 - 6 } & $\mathbf{f}$ & $\mathbf{\%}$ & $\mathbf{f}$ & $\mathbf{\%}$ & $\mathbf{f}$ & $\mathbf{\%}$ & \\
\hline Tidak Andal & 38 & 45,8 & 17 & 20,5 & 55 & 66,3 & \multirow{2}{*}{0,010} \\
Andal & 27 & 32,5 & 1 & 1,2 & 28 & 33,7 & \\
\hline Total & $\mathbf{6 5}$ & $\mathbf{7 8 , 3}$ & $\mathbf{1 8}$ & $\mathbf{2 1 , 7}$ & $\mathbf{8 3}$ & $\mathbf{1 0 0 , 0}$ & \\
\hline
\end{tabular}

Tabel 3. Hubungan Assurances dengan Mutu Pelayanan di Instalasi Rawat Jalan Rumah Sakit Stella Maris Bintang Laut Kecamatan Teluk Dalam Kabupaten Nias Selatan

\begin{tabular}{|c|c|c|c|c|c|c|c|}
\hline \multirow{3}{*}{ Assurance } & \multicolumn{4}{|c|}{ Mutu Pelayanan } & \multirow{2}{*}{\multicolumn{2}{|c|}{ Total }} & \multirow{3}{*}{$p$ value } \\
\hline & \multicolumn{2}{|c|}{ Kurang } & \multicolumn{2}{|c|}{ Baik } & & & \\
\hline & $\mathbf{f}$ & $\%$ & $\mathbf{F}$ & $\%$ & $\mathbf{f}$ & $\%$ & \\
\hline Kurang Pasti & 33 & 39,8 & 15 & 18,1 & 48 & 57,8 & \\
\hline Pasti & 32 & 38,6 & 3 & 3,6 & 35 & 42,2 & 0,027 \\
\hline Total & 65 & 78,3 & 18 & 21,7 & 83 & 100,0 & \\
\hline
\end{tabular}

Tabel 4. Hubungan Tangible dengan Mutu pelayanan di Instalasi Rawat Jalan Rumah Sakit Stella Maris Bintang Laut Kecamatan Teluk Dalam Kabupaten Nias Selatan

\begin{tabular}{|c|c|c|c|c|c|c|c|}
\hline \multirow{3}{*}{ Tangible } & \multicolumn{4}{|c|}{ Mutu Pelayanan } & \multirow{2}{*}{\multicolumn{2}{|c|}{ Total }} & \multirow{3}{*}{$p$ value } \\
\hline & \multicolumn{2}{|c|}{ Kurang } & \multicolumn{2}{|c|}{ Baik } & & & \\
\hline & $\mathbf{f}$ & $\%$ & $\mathbf{f}$ & $\%$ & $\mathbf{f}$ & $\%$ & \\
\hline Kurang Baik & 48 & 57,8 & 3 & 3,6 & 51 & 61,4 & \\
\hline Baik & 17 & 20,5 & 15 & 18,1 & 32 & 38,6 & 0,000 \\
\hline Total & 65 & 78,3 & 18 & 21,7 & 83 & 100,0 & \\
\hline
\end{tabular}

Tabel 5. Hubungan Empathy dengan Mutu pelayanan di Instalasi Rawat Jalan Rumah Sakit Stella Maris Bintang Laut Kecamatan Teluk Dalam Kabupaten Nias Selatan

\begin{tabular}{|c|c|c|c|c|c|c|c|}
\hline \multirow{3}{*}{ Empaty } & \multicolumn{4}{|c|}{ Mutu Pelayanan } & \multirow{2}{*}{\multicolumn{2}{|c|}{ Total }} & \multirow{3}{*}{$p$ value } \\
\hline & \multicolumn{2}{|c|}{ Kurang } & \multicolumn{2}{|c|}{ Baik } & & & \\
\hline & $\mathbf{f}$ & $\%$ & f & $\%$ & $\mathbf{f}$ & $\%$ & \\
\hline Kurang Perhatian & 46 & 55,4 & 7 & 8,4 & 53 & 63,9 & 0,027 \\
\hline
\end{tabular}




\begin{tabular}{cccccccc} 
Perhatian & 19 & 22,9 & 11 & 13,3 & 30 & 36,1 & \\
\hline Total & $\mathbf{6 5}$ & $\mathbf{7 8 , 3}$ & $\mathbf{1 8}$ & $\mathbf{2 1 , 7}$ & $\mathbf{8 3}$ & $\mathbf{1 0 0 , 0}$ \\
\hline
\end{tabular}

Tabel 6. Hubungan Responsiveness dengan Mutu pelayanan di Instalasi Rawat Jalan Rumah Sakit Rumah Sakit Stella Maris Bintang Laut Kecamatan Teluk Dalam Kabupaten Nias Selatan

\begin{tabular}{ccccccccc}
\hline \multirow{2}{*}{ Responsiveness } & \multicolumn{4}{c}{ Mutu Pelayanan } & \multicolumn{2}{c}{ Total } & \multirow{2}{*}{$\boldsymbol{p}$ value } \\
\cline { 2 - 7 } & \multicolumn{2}{c}{ Kurang } & \multicolumn{2}{c}{ Baik } & & & \\
\cline { 2 - 7 } & $\mathbf{f}$ & $\mathbf{\%}$ & $\mathbf{f}$ & $\mathbf{\%}$ & $\mathbf{f}$ & $\mathbf{\%}$ & \\
\hline Kurang Tanggap & 48 & 57,8 & 4 & 4,8 & 52 & 62,7 & \multirow{2}{*}{0,000} \\
Tanggap & 17 & 20,5 & 14 & 16,9 & 31 & 37,3 & \\
\hline Total & $\mathbf{6 5}$ & $\mathbf{7 8 , 3}$ & $\mathbf{1 8}$ & $\mathbf{2 1 , 7}$ & $\mathbf{8 3}$ & $\mathbf{1 0 0 , 0}$ & \\
\hline
\end{tabular}

\section{Analisis Multivariat}

Tabel 7.Hasil Analisis Uji Regresi Logistik Faktor-Faktor yang Berhubungan dengan Mutu Pelayanan Kesehatan Di Rumah Sakit Stella Maris Bintang Laut Kecamatan Teluk Dalam Kabupaten Nias Selatan

\begin{tabular}{ccccccccc}
\hline No & Variabel & B & S.E. & Wald & df & Sig & $\operatorname{Exp}(\mathbf{B})$ & $\mathbf{9 5 \%}$ \\
\hline 1 & Reliability & 2.775 & 1.331 & 4.348 & 1 & 0,037 & 0,062 & $0,005-0,847$ \\
2 & Assurance & 1.726 & 0,943 & 3.348 & 1 & 0,064 & 0,178 & $0,028-1,131$ \\
3 & Tangibles & 1.206 & 1.074 & 1.263 & 1 & 0,261 & 3,341 & $0,407-27,394$ \\
4 & Empathy & 1.099 & 1.307 & 0,707 & 1 & 0,400 & 0,333 & $0,026-4,317$ \\
5 & Responsiveness & 3.370 & 1.619 & 4,335 & 1 & 0,037 & 29,081 & $1,219-694,035$ \\
\hline
\end{tabular}

Tabel 8. Hasil Analisis Uji Regresi Logistik Faktor- Faktor yang Berhubungan dengan Mutu Pelayanan Kesehatan Di Rumah Sakit Stella Maris Bintang Laut Kecamatan Teluk Dalam Kabupaten Nias Selatan

\begin{tabular}{ccccccccc}
\hline No & Variabel & B & S.E. & Wald & df & Sig & $\operatorname{Exp}(\mathbf{B})$ & $\mathbf{9 5 \%}$ \\
\hline 1 & Reliability & 3,033 & 0,915 & 6,459 & 1 & 0,011 & 0,187 & $0,031-1,121$ \\
2 & Assurance & 1,679 & 0,825 & 3,366 & 1 & 0,064 & 0,048 & $0,005-0,500$ \\
3 & Responsiveness & 3,424 & 1,194 & 17,225 & 1 & 0,000 & 30,691 & $6,092-$ \\
& & & & & & & & \\
\hline
\end{tabular}

\section{Pembahasan}

Hubungan Reliability dengan Mutu pelayanan di Instalasi Rawat Jalan Rumah Sakit Stella Maris Bintang Laut Kecamatan Teluk Dalam Kabupaten Nias Selatan

Hasil uji statistik menunjukkan bahwa ada pengaruh yang signifikan antara reliability dengan mutu pelayanan di Instalasi Rawat Jalan Rumah Sakit Stella Maris Bintang Laut Kecamatan Teluk Dalam Kabupaten Nias Selatan dengan nilai $p=0,010<$ 0,05 .

Hasil penelitian Hasbina Wildani dkk menunjukkan bahwa faktor yang berhubungan dengan kepuasan pasien rawat jalan adalah tangibles $(\mathrm{p}=0,016)$, realibility $(\mathrm{p}=0,021)$, responsiveness $(\mathrm{p}=0,001)$, assurance $(\mathrm{p}=0,001)$, dan empathy $(\mathrm{p}=0,001)$. Kesimpulan diperoleh bahwa adalah ada hubungan tanglibility, reliability, responsiveness, assurance dan empathy dengan kepuasan pasien rawat jalan. Diharapkan bagi rumah sakit untuk mempertahan pelanggan dan menambah jumlah kunjungan yaitu dengan 
meningkatkan kualitas pelayanan dan melengkapi prasarana yang masih kurang, sehingga kepuasan pasien terpenuhi dan pasien menjadi loyal (10).

Hubungan Assurance dengan Mutu pelayanan di Instalasi Rawat Jalan Rumah Sakit Stella Maris Bintang Laut Kecamatan Teluk Dalam Kabupaten Nias Selatan

Hasil uji statistik menunjukkan bahwa ada pengaruh yang signifikan antara assurance dengan mutu pelayanan di Instalasi Rawat Jalan Rumah Sakit Stella Maris Bintang Laut Kecamatan Teluk Dalam Kabupaten Nias Selatan dengan nilai $p=0,027<$ 0,05 .

Hasil penelitian yang dilakukan oleh Syahputra (2015) menyatakan bahwa dimensi jaminan belum diterapkan secara maksimal oleh BPJS Kesehatan. Peneliti menganalisa bahwa pasien merasa kinerja petugas kesehatan kurang sopan, dan ramah. (11).

Hubungan Tangibles dengan Mutu pelayanan di Instalasi Rawat Jalan Rumah Sakit Stella Maris Bintang Laut Kecamatan Teluk Dalam Kabupaten Nias Selatan

Hasil uji statistik menunjukkan bahwa ada pengaruh yang signifikan antara tangibles dengan mutu pelayanan kesehatan di Rumah Sakit Stella Maris Bintang Laut Kecamatan Teluk Dalam Kabupaten Nias Selatan dengan nilai $p=0,000<0,05$.

Penelitian ini didukung oleh Toar W. J. Hatibie, yang menyatakan bahwa terdapat hubungan yang signifikan dari variabel bukti fisik (nilai $p=0,020$ ), kehandalan (nilai $p=$ 0,006), dan perhatian (nilai $\mathrm{p}=0,000$ ) dengan kepuasan pasien. Penelitian juga menunjukkan tidak ada hubungan antara Variabel daya tanggap (nilai $\mathrm{p}=0,109$ ) dan jaminan (nilai $\mathrm{p}=0,335$ ) dengan kepuasan pasien. Berdasarkan hasil analisis multivariat didapatkan bahwa perhatian (emphaty) merupakan variabel yang dominan terhadap kepuasan pasien di Instalasi Rawat Jalan Bedah RSUP Prof. Dr. R. D. Kandou Manado $(\mathrm{OR}=4,935,95 \% \mathrm{CI}: 1,902-12,805)(12)$.

Hubungan Empathy dengan Mutu pelayanan di Instalasi Rawat Jalan Rumah Sakit Stella Maris Bintang Laut Kecamatan Teluk Dalam Kabupaten Nias Selatan

Hasil uji statistik menunjukkan bahwa ada pengaruh yang signifikan antara empathy dengan mutu pelayanan di Instalasi Rawat Jalan Rumah Sakit Stella Maris Bintang Laut Kecamatan Teluk Dalam Kabupaten Nias Selatan dengan nilai $p=0,027<0,05$.

Penelitian ini sejalan dengan penelitian yang dilakukan oleh Yuniarti (2015) yang menyatakan bahwa ada hubungan antara mutu pelayanan rumah sakit pada dimensi empathy dengan tingkat kepuasan pasien BPJS dengan nilai p sebesar $0,000(\mathrm{p}<0,05)$.

Hubungan Responsiveness dengan Mutu pelayanan di Instalasi Rawat Jalan Rumah Sakit Stella Maris Bintang Laut Kecamatan Teluk Dalam Kabupaten Nias Selatan

Hasil uji statistik menunjukkan bahwa ada pengaruh yang signifikan antara responsiveness dengan mutu pelayanan di Instalasi Rawat Jalan Rumah Sakit Stella Maris Bintang Laut Kecamatan Teluk Dalam Kabupaten Nias Selatan dengan nilai $p=0,000<$ 0,05 .

Hasil penelitian yang telah dilakukan di RSUD Langsa ditemukan bahwa daya tanggap memiliki pengaruh signifikan terhadap kepuasan pasien. Berdasarkan hasil distribusi frekuensi daya tanggap didapati sebanyak 57,0\% responden di RSUD Langsa menyatakan kurang baik. (11).

Faktor Paling Dominan yang Berhubungan dengan Mutu Pelayanan di Instalasi Rawat Jalan Rumah Sakit Stella Maris Bintang Laut Kecamatan Teluk Dalam Kabupaten Nias Selatan 
Hasil penelitian menunjukkan bahwa dari uji regresi logistik faktor paling dominan yang berhubungan dengan mutu pelayanan adalah variabel responsivenes $p=0,000<0,05$ dan 95\% 95\% CI $=6,092-154,611$ artinya responsivenes ada hubungan dengan mutu pelayanan di Instalasi Rawat Jalan Rumah Sakit Stella Maris Bintang Laut Kecamatan Teluk Dalam Kabupaten Nias Selatan.

\section{Kesimpulan}

Berdasarkan hasil penelitian, maka dapat disimpulkan bahwa ada hubungan antara faktor Reliability, Assurance, Tangibles, Empathy, Responsiveness terhadap mutu pelayanan kesehatan di Rumah Sakit Stella Maris Bintang Laut.

\section{Daftar Pustaka}

Nova, R. F. Pengaruh Kualitas Pelayanan Terhadap Kepuasan Pasien Rawat Inap Pada Rumah Sakit. Muhammadiyah Surakarta. 2010;210.

Mental A. World Health Organization. 2003;1-8.

Ridwan, I., \& Saftarina, F. (2015). Pelayanan Fasilitas Kesehatan: Faktor Kepuasan dan Loyalitas Pasien. Jurnal Majority, 4(9), 20-26.

Indonesia Mkr. Peraturan Menteri Kesehatan Republik Indonesia Nomor 1171/Menkes/Per/Vi/2011. 2011;2-5.

Siyen, S., Hadi, A. J., \& Asriwati, A. (2020). Faktor Yang Berhubungan Dengan Mutu Pelayanan Rumah Sakit Bhayangkara Tebing Tinggi. MPPKI (Media Publikasi Promosi Kesehatan Indonesia): The Indonesian Journal of Health Promotion, 3(3), 267-274.

Sugiyono, (2008). Metode Penelitian Kuantitatif Kualitatif dan R\&D. CV. Alfabeta, Bandung..

Afrilianti, A. N. Kepuasan Pasien terhadap Mutu Pelayanan Rawat Inap berdasarkan Metode ServQual di Rumah Sakit Umum Daerah Cilegon Tahun 2014.

Siyen, S., Hadi, A. J., \& Asriwati, A. (2020). Faktor Yang Berhubungan Dengan Mutu Pelayanan Rumah Sakit Bhayangkara Tebing Tinggi. MPPKI (Media Publikasi Promosi Kesehatan Indonesia): The Indonesian Journal of Health Promotion, 3(3), 267-274.

Leu Fy, Pai Cc. Analisis Regresi Multivariat Berdasarkan Faktor-Faktor Yang Mempengaruhi Derajat Kesehatan Di Provinsi Jawa Timur. 5th Int Conf Inf Assur Secur Ias 2009. 2017;2:255-8.

Wildani H, Badiran M, Hadi Aj. Hubungan Kualitas Pelayanan Kesehatan Rawat Jalan Dengan Tingkat Kepuasan Pasien Peserta Jaminan Kesehatan Nasional Di Rsu Muhammadiyah Sumatera Utara. J Komunitas Kesehat Masy. 2020;1(2):7-21.

Fadillah M. Pengaruh Kualitas Pelayanan Terhadap Kepuasan Peserta Bpjs Di Rumah Sakit Umum Daerah Langsa Tahun 2017. Jkmm. 2018;3(11):291-300.

W.J. Habitie T, Rattu Aj., Pasiak T. Analisis Faktor-Faktor Yang Berhubungan Dengan Kepuasan Pasien Di Instalasi Rawat Jalan Bedah Rsup Prof. Dr. R. D. Kandau Manado. Jikmu. 2015;5(2a):302-10. 